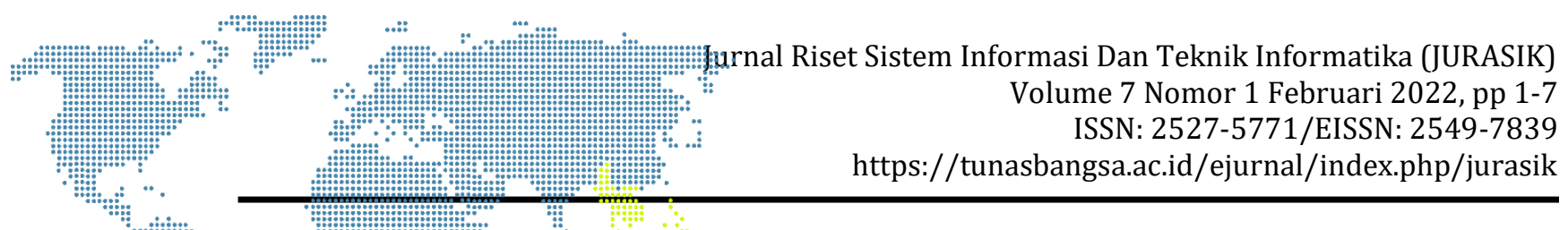

\title{
Sistem Informasi SMP Negeri 5 Walenrang Berbasis
} Web

\author{
Wahyu Saputra ${ }^{1}$, Apriyanto ${ }^{2}$, Solmin Paembonan ${ }^{3}$ \\ 1,2,3Universitas Andi Djemma Palopo, Palopo
}

saputrawy00@gmail.com ${ }^{1}$, riyadh.math06@gmail.com², solminpaembonan@gmail.com³

\begin{abstract}
This study aims to create and implement a web-based information system for SMP Negeri 5 Walenrang. The type of research used in this study is Research And Development (R\&D) with data collection techniques using observation methods, documentation methods, and interview methods. The web-based information system of SMP Negeri 5 Walenrang is designed using the UML (Unified Modeling Language) model which consists of use case diagrams, activity diagrams, sequence diagrams and class diagrams. The information system that is built is web-based using the PHP programming language and MySQL database. The results of this information system are login page, profile input page, news publication input page, agenda input page, activity schedule input page, news input page, student input page, lesson input page, input page, grades, lesson input page, input page schedule, home page, profile page, news publication view page, agenda page, gallery page, grade view page, schedule view page, teacher data page. This system has been tested using black box testing, where all tested displays are guilty as desired.
\end{abstract}

Keywords: SMPN 5 Walenrang, PHP, UML

\section{Abstrak}

Penelitian ini bertujuan untuk membuat dan mengimplementasikan sistem informasi SMP Negeri 5 Walenrang berbasis web. Jenis penelitian yang digunakan dalam penelitian ini adalah Research And Development (R\&D) dengan teknik pengumpulan data menggunakan metode observasi, metode dokumentasi, dan metode wawancara. sistem informasi SMP Negeri 5 Walenrang berbasis web dirancang menggunakan model UML (Unified Modeling Language) yang terdiri dari use case diagram, acvtivity diagram, sequence diagram dan class diagram. Sistem informasi yang dibangun berbasis web menggunakan Bahasa pemrograman PHP dan database MySQL. Hasil dari sistem informasi ini berupa halaman login, halaman input profil, halaman input publikasi berita, halaman input agenda, halaman input jadwal kegiatan, halaman input berita, halaman input siswa, halaman input pelajaran, halaman input, nilai, halaman input pelajaran, halaman input jadwal, halaman home, halaman porfil, halaman lihat publikasi berita, halaman agenda, halaman galeri, halamanlihat nilai, halaman lihat jadwal, halaman data guru. Sistem ini telah diuji menggunakan pengujian black box, dimana semua tampilan yang diuji bersalah sesuai yang diinginkan.

Kata kunci: SMPN 5 Walenrang, PHP, UML

\section{PENDAHULUAN}

Kecanggihan teknologi dimasa sekarang ini sangat berkembang pesat begitu pun dengan informasi yang penyebarannya semakin banyak. Ruang lingkup pendidikan harus dapat mengikuti kemajuan teknologi tersebut. Adanya internet informasi begitu mudah untuk dipenuhi terutama dalam dunia pendidikan, sehingga dalam hitungan detik informasi dapat dibagi dan didapatkan [1]. Teknologi infomasi telah banyak dimanfatkan oleh instansi pada masa sekarang, misalanya pemanfaatan teknologi informasi berbasis yang web sebagai media untuk menyampaikan informasi. Adanya teknologi informasi ini sangat bermanfaat bagi pihak sekolah, sehingga pihak sekolah bisa melakukan atau membagikan 


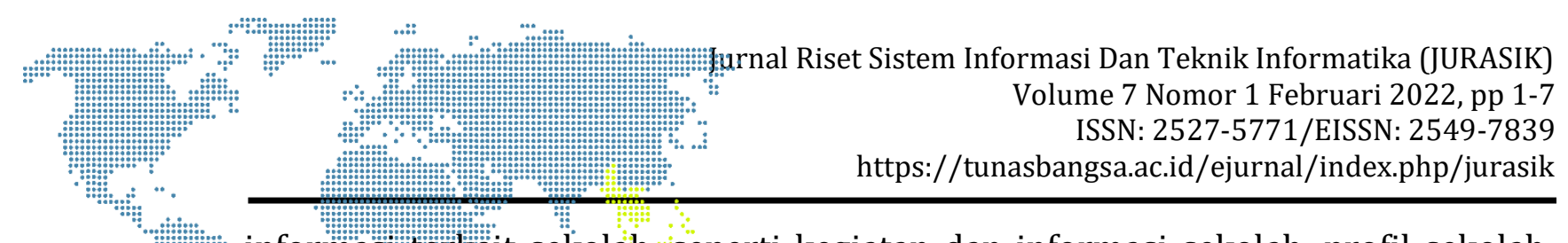

informaș ter lkait sekolah, seperti kegiatan dan informasi sekolah, profil sekolah, maupun detata:guru dan siswa; yang berkaitan dengan sekolah yang dapat diakses secara online.

SMP Negeri 5 Walenrang 'alah sekolah yang dinaungi Dinas Pendidikan dan Olahraga, dan sekolah ini belum memeliki website sebagai saran untuk menyampaikan informasi, sehingga masayarkat belum banyak mengetahui tentang SMP Negeri 5 Walenrang. Penerapan sistem informas di SMP Negeri 5 Walenrang masih menggunakan manual seperti biasanya para siswa atau masyarakat yang akan mendapatkan informasi harus datang ke sekolah untuk mengatahui informasi atau pengumuman terkait kegiatan sekolah, meraka harus berhubungan langsung kepada salah satu pegawai atau guru di sekolah, hal seperti itu tidak efisien karena pada masa sekarang adalah masa pandemic Covid-19 yang tidak diperbolehkan untuk berkumpul atau bertatapat muka di sekolah. Sehingga dengan adanya sistem informasi yang berbasis web di SMP Negeri 5 Walenrang diharapkan segala kegiata-kegiatan dan pemberian informasi sekolah dapat ditampilkan secara up to date. Peneliti menyempatkan diri melakukan observasi di SMP Negeri 5 Walenrang dengan bertanya kepada beberapa guru dan kepala sekolah, dimana terdapat banyak kendala seperti informasi yang tidak terupdate dan tidak memiliki sarana dalam memberikan informasi mengenai profil sekolah secara online di internet. Sehingga website ini nantinya, dapat dengan mudah diakses oleh masyarakat dan siswa. Selanjutnya dalam penelitian penulis menggunakan metode R\&D di karenakan cocok dan sesuai dengan peneliti yang akan lakukan yaitu penelitian pengembangan, penilti berencana melakukan pengembangan terhadap sistem yang ada di SMP Negeri 5 Walenrang.

Pentingya website ini juga harus dibarengi dengan penggunaan alat yang mendukung agar dapat memperbaiki kebutuhan bagi sekolah. Berdasarkan uraian diatas, peneliti merumuskan permasalahan bagaimana membuat dan Implementasi sistem informasi SMP Negeri 5 Walenrang berbasis web ? dengan tujuan penelitian yaitu mencapai rumusan masalah.

\section{METODOLOGI PENELITIAN}

\subsection{Perancangan}

Perancangan mempunyai 2 arti, yang pertama adalah agar menyelesaikan keinginan pengguna dari sistem yang dibuat dan kedua dapat memberikan bentuk dari sistem untuk semua serta yang terlibat didalamnya [2]. Nasir dan Anwar menjelaskan bahwa perancangan adalah salah satu kegiatan untuk mendesign atau mendeskripsikan sistem yang baru sehinnga menyelesaikan masalah yang ada pada suatu perusahaan [3]. Sedangkan pendapat berbeda mengemukakan bahwa perancangan sistem merupakan tahapan setelah analisis sistem, dimana untuk menggambarkan sistem yang baru dibentuk dan mendefenisikan kebutuhan fungsional sebagai persiapan rancangan dalam pembuatan aplikasi [4]. Sehingga dapat dismpulkan bahwa perancnagan adalah desain awal yang dilakukan untuk membangun atau membuat sistem yang baru dan mengganti sistem yang lama. 


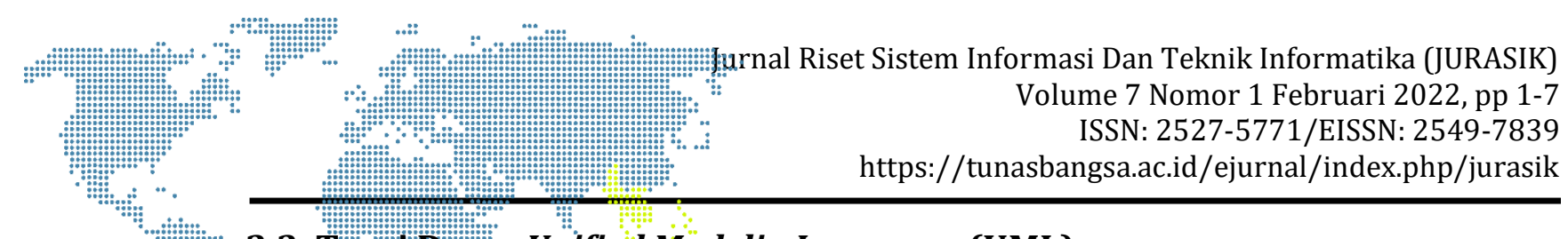

\subsection{Teor Dasar Unified Modelin Language (UML)}

Uniteded Modeling Language (UML) merupakan alat bantu yang dapat digunakan untuk mendêsam sistem dan dapat diaplikasikan pada bahasa pemograman yang berorientási objek, saat ini UML sudah mulai menjadi standar bagi industri pengembangan sistem/perangkat lunak yang berorientasi objek karena pada dasarnya UML digunakan oleh banyak perusahaan raksasa untuk pengembangan perangkat lunak [5].

\subsection{Sistem Basis Data dan My SQL}

Sistem basis data adalah sistem yang terdiri atas kumpulan file (tabel) yang saling berhubungan (dalam sebuah basis data di bawah sistem komputer) dan sekumpulan program (DBMS: Database Managenent System) yang memungkinkan beberapa pemakai dan/atau program lain untuk mengakses dan memanipulasi file-file (tabel-tabel) tersebut [6].

Sedangkan MySQL adalah multiuser database yang menggunakan Structured Query Language (SQL). MySQL merupakan software sistem manajemen database (database management system - DBMS). MySQL awalnya dibuat oleh perusahaan konsultan bernama TcX yang berlokasi di swedia. Saat ini, pengembangan MySQL berada dibawah naungan perusahaan MySQL AB [7]. Adapun pendapat yang berbeda, MySQL adalah sistem manajemen database SQL yang bersifat Open Source dan paling populer saat ini. Sistem database MySQL mendukung beberapa fitur seperti multithreaded, multi-user dan SQL database management system (BDMS). Database ini dibuat untuk keperluan sistem database yang cepat, handal dan mudah digunakan [8].

\subsection{Hypertext Markup Language (HTML)}

HTML yang mempunyai kepanjangan Hyper Text Markup Language yang merupakan struktur awal akan dari aplikasi website, karena html memiliki fungsi untuk menjadi kerangka ataupun model web yang digunakan untuk menampilkan informasi di dalam halaman web atau browser [7].

\subsection{Pengujian Sistem (Black Box)}

Black Box berfokus hadirat serpih fungsional berusul perlengkapan lunak. Tester bisa memerikan pawai bab input dan mengamalkan penjajalan hadirat serpih fungsional program. Black-Box menjadikan percobaan yang berfokus hadirat serpih fungsional berusul perlengkapan lunak, penguji bisa memerikan pawai bab input dan mengamalkan penjajalan hadirat serpih fungsional program. Black Box bukanlah pemecahan preferensi berusul White Box tapi lebih menjadikan komplemen kepada mengetes ayat-ayat yang tidak dicakup oleh White Box [9].

\subsection{Analisis Fungsional MC. Cal}

Aprilian mengatakan bahwa analisis fungsional MC. Cal merupakan salah satu pendekatan atau metode yang didalamnya terdapat beberapa karakteristik 


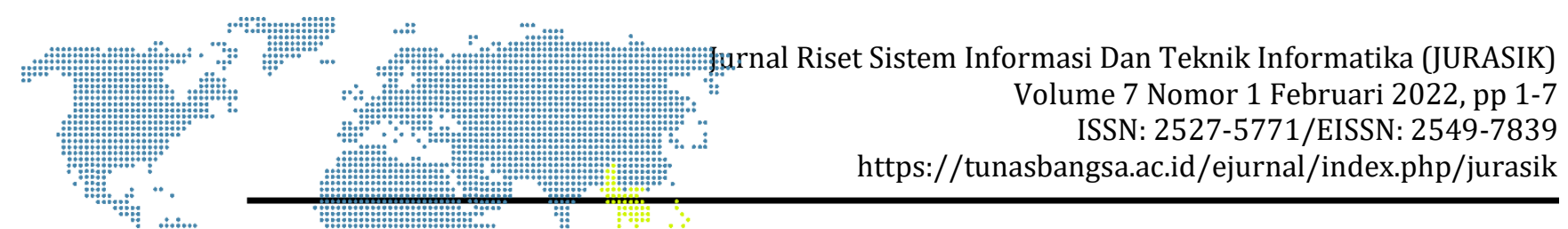

sebagai model untuk menilai dan memastikan kualitas pada software [10]. Berikut Gambar 1 yang merupakan gantbar kategori analisis fungsional MC. Cal:

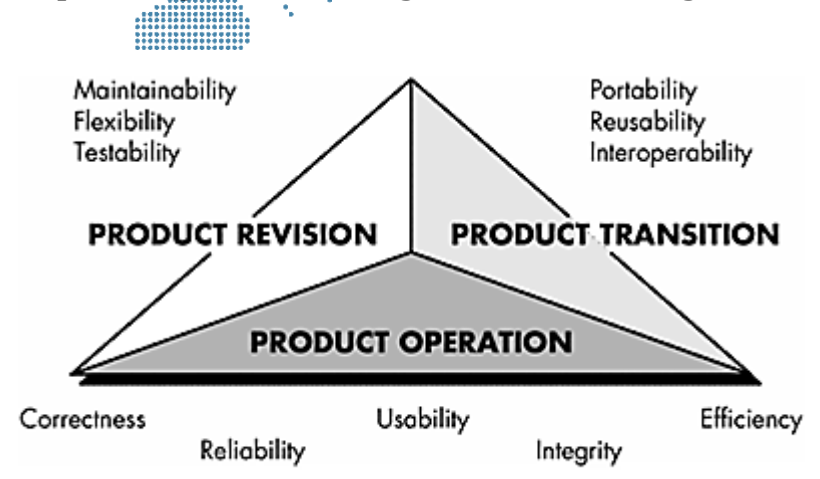

Gambar 1. Kategori analisis fungsional MC. Cal

\subsection{Metode Research and Development (R\&D)}

Metode Research \& Development (R\&D) adalah metode penelitian yang menghasikan sebuah produk dalam bidang keahlian tertentu, yang diikuti produk sampingan tertentu serta memiliki efektifitas dari sebuah produk tersebut [11]. Pendapat yang berbeda research and development (R\&D) yang merupakan desain penelitian dan pengembangan, yaitu metode penelitian yang digunakan untuk menghasilkan produk tertentu dan menguji keefektifan produk tersebut [12].

Berdasarkan bebarapa pendapat diata Research and Development (R\&D) metode atau desin penelitian yang memiliki proses atau langkah-langka dalam penelitian yang dapat menghasilkan produk tertentu dan juga menguji keefektifan produ tersebut.

\subsection{Perancangan Sistem}

\subsubsection{Sistem yang Berjalan}

Analisis sistem yang berjalan SMP Negeri 5 Walenrang masih bersifat manual, Sehingga data sekolah atau informasi sekolah masih disimpan dalam kertas yang telah di print out dan diarsipkan pada lemari arsip, sehingga sering terjadi keterlambatan pencarian data dan kesalahan dalam pengelolan data, sistem berjalan terlihat pada Gambar 2.

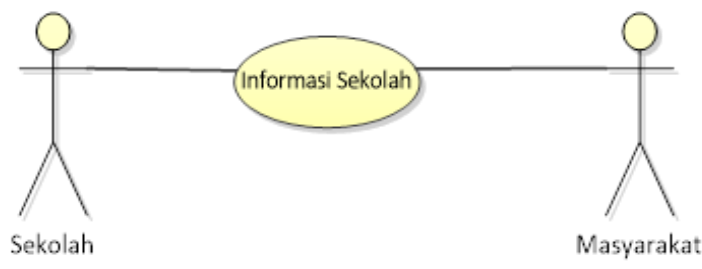

Gambar 2. Sistem yang berjalan

\subsubsection{Sistem yang Diusulkan}

Berdasarkan Gambar 3. sistem uang diusulkan teridiri dari 4 aktor yang terlibat yaitu admin, siswa, orang tua, dan kepala sekolah, masing actor dapat mengakses sistem sesuai kebutuhan mereka. 


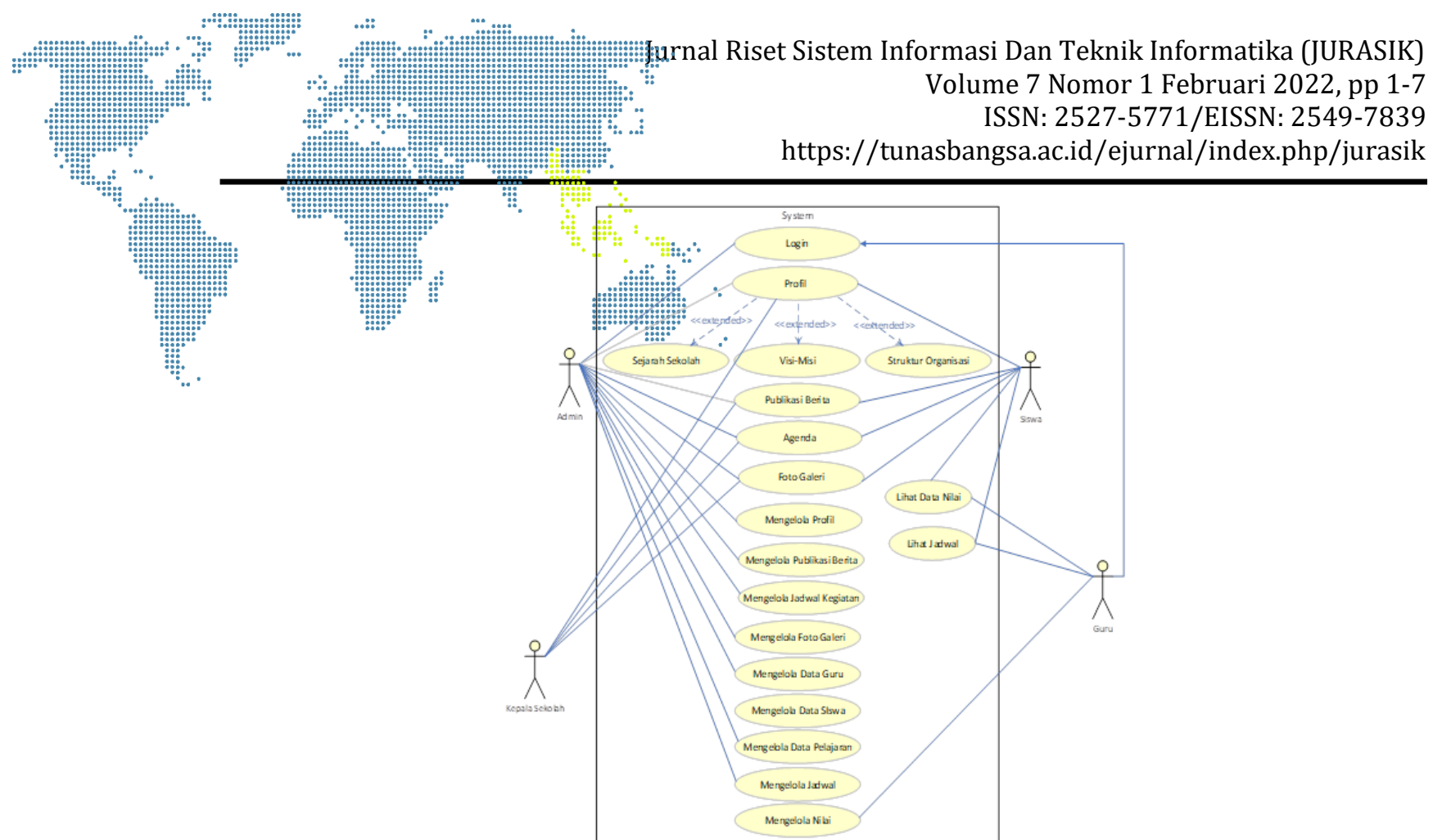

Gambar 3. Sistem yang diusulkan

\section{HASIL DAN PEMBAHASAN}

Hasil rancangan interface pada sistem informasi smp negeri 5 walenrang berbasis web.
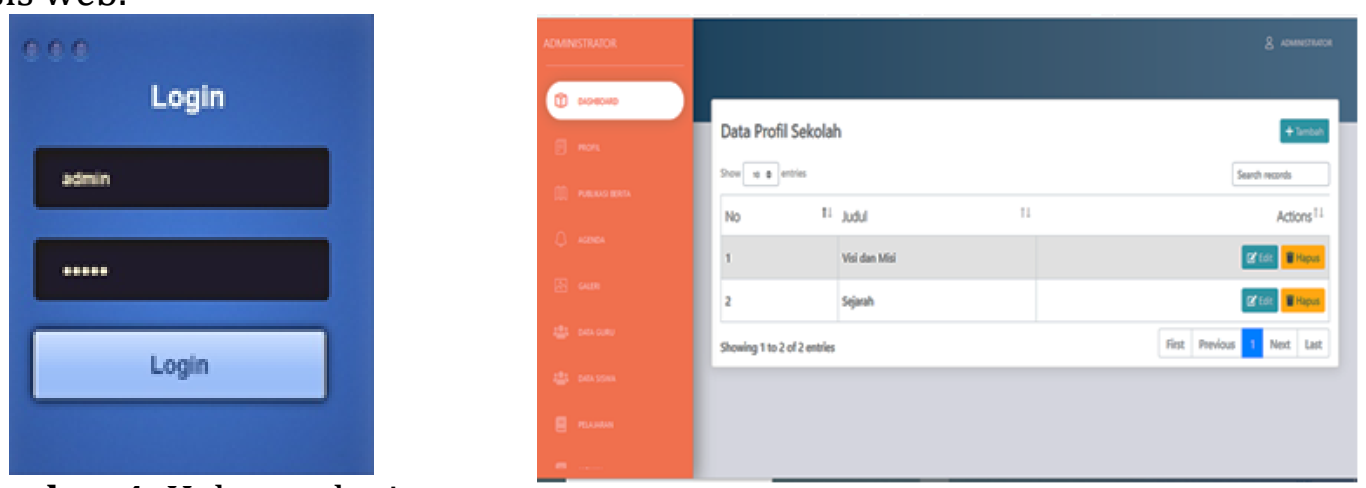

Gambar 4. Halaman login

Gambar 5. Halaman Kelola profil

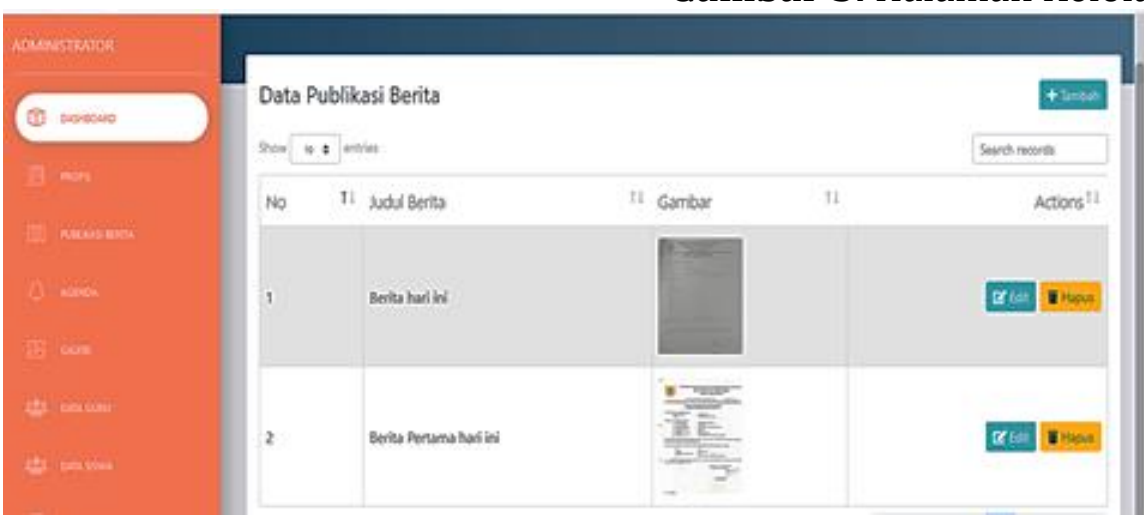

Gambar 6. Tampilan Kelola publikasi 

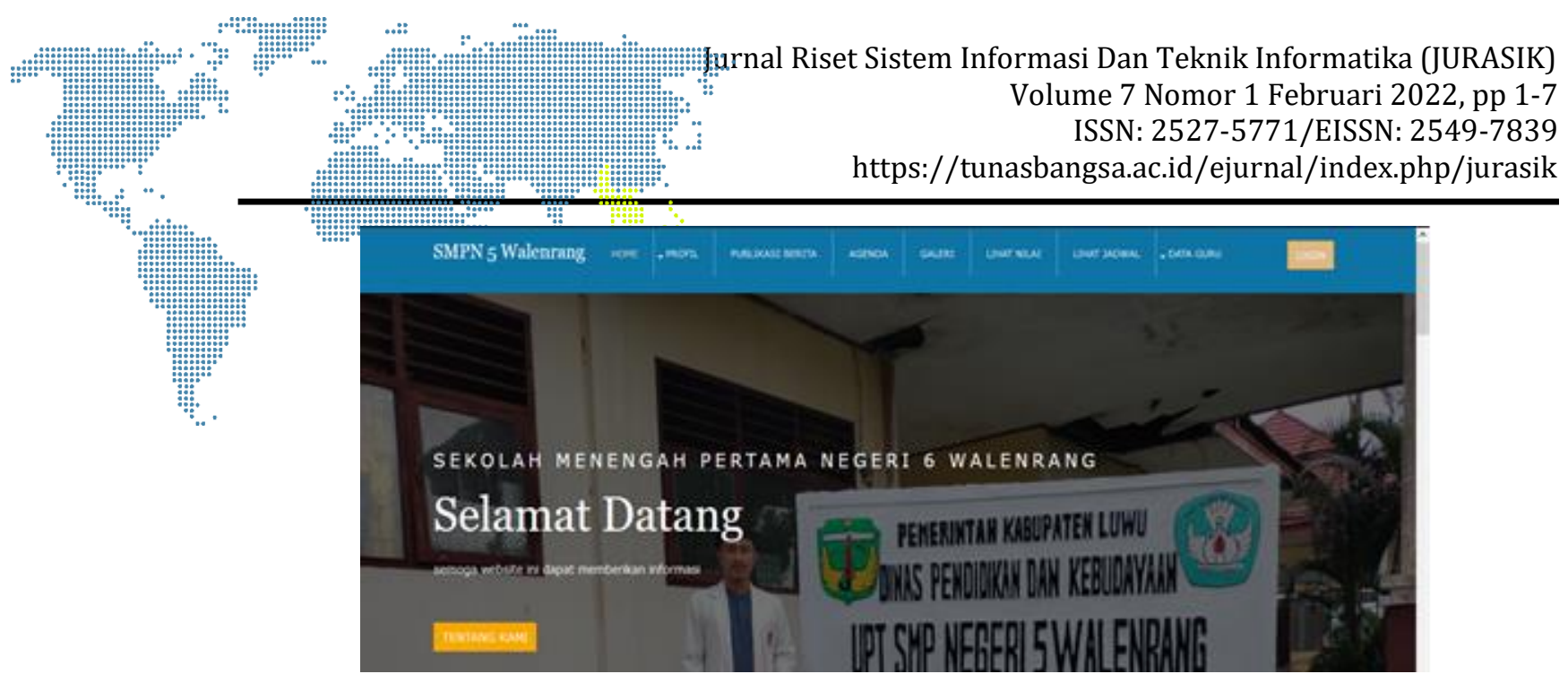

Gambar 7. Tampilan home

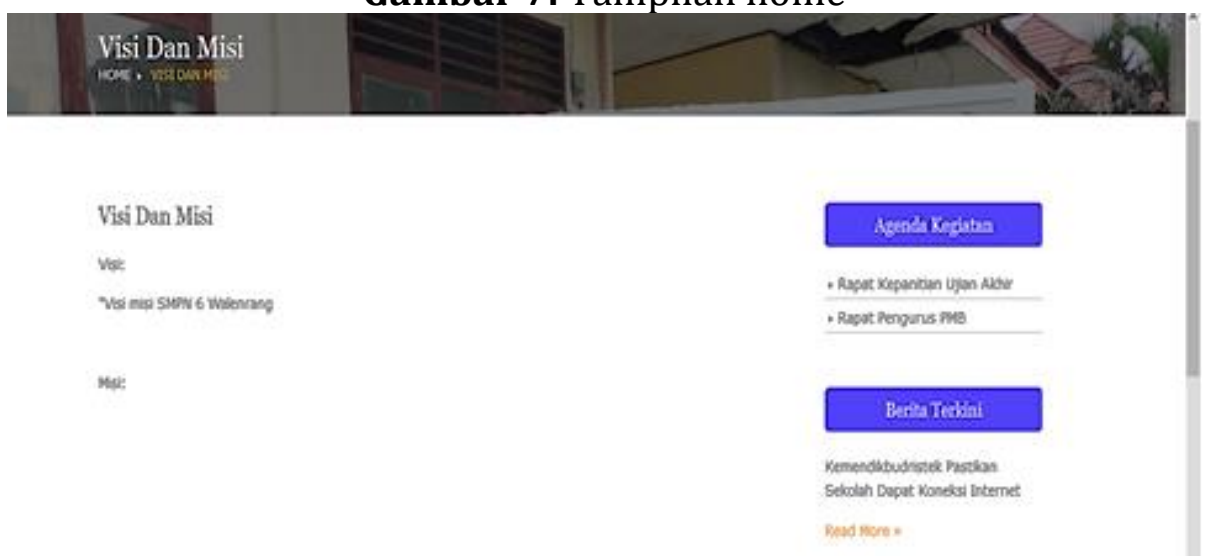

Gambar 8. Tampilan halaman profil

\section{SIMPULAN}

Kesimpulan dari penelitian yang dilakukan peneliti adalah sebagai berikut:

a) Sistem yang dirancang untuk SMP Negeri 5 Walenrang berbasis web menggunakan model UML, Adapun rancangan modelnya adalah diagram use case, diagram activity, diagram sequence, serta diagram class.

b) Sistem informasi SMP Negeri 5 Walenrang berbasis web dibuat dengan memakai bahasa pemrograman PHP dengan versi 7 sedangkan untuk media penyimpanan data memakai database Mysql dengan Versi 5.6. Adapun hasili dari pembuatan sistem informasi SMP Negeri 5 Walenrang yang berbasis web terdiri dari halaman login, Kelola profil, Kelola publkasi berita, kelolajadwal kegaitan, Kelola foto galeri, data guru, data siswa, kelola palajaran, jadwal, kelola nilai, lihat profil, lihat publikasi berita, agenda, foato galeri, lihat jadwal dan lihat nilai.

c) Hasil implementasi sistem dilakukan dengan melakukan pengujian usability sistem. Pengujian usability berdasarkan kuesioner yang telah dibagikan kepada beberapa resonden yang ada di SMP Negeri 5 Walenrang. Berdasarkan pengujian usability didapatkan nilai persentasi dari sistem yang telah dibuat sebesar 90,71\%, sehingga standar kelayakan yang didapatkan adalah sangat layak. 


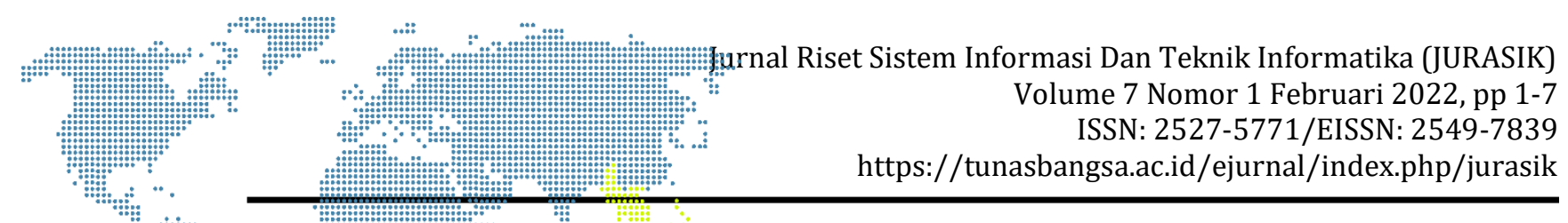

\section{DAFTAR PUSTAKA}

[1] Anam dan Muharram, "Analisa Dan Perancangan Sistem Informasi Akademik

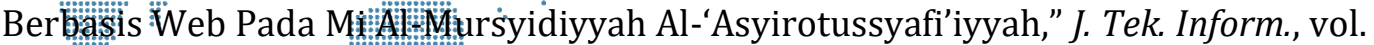
11, 2018, " [Online]. Available: http: //journal.uinjkt.ac.id/index.p̈hp/ti/article/download/8867/pdf.

[2] Sukadi dan Mujiati, "Analisis dan Perancangan Sistem Informasi Stok Obat Pada Apotek Arjowinangun," Indones. J. Comput. Sci., 2017, [Online]. Available: https: //ijns.org/journal/index.php/ijns/article/view/279/273.

[3] Nasir dan Anwar, "Perancangan Sistem Pembayaran Sumbangan Pembangunan Pendidikan (SPP) Dan Ber-Registrasi Pada Uniersitas Cokroaminoto Palopo Berbasis Client-Server," J. d'computar'E, vol. 3, 2013.

[4] Hardiana, "Perancangan Aplikasi Penjualan Motor Bekas Berbasis Web Pada Toko Ainun Masamba," J. d'computarE, vol. 4, 2014.

[5] Wahono, Rekayasa Perangkat Lunak Menggunakan UML dan Java. Yogyakarta: Andi Offset, 2013.

[6] Andrasto, "Pengembangan Sistem Database Hasil Penelitian Dan Pengabdian Kepada Masyarakat Dosen Unnes," J. Tek. Elektro, vol. 5, no. 2, 2013, [Online]. Available: https: //media.neliti.com/media/publications/133277-IDpengembangan-sistem-database-hasil-penel.pdf.

[7] Purbadian, Aplikasi Penjualan Web Base dengan PHP untuk Panduan Skripsi. Cirebon: CV. Asfa Solution, 2015.

[8] Madcoms, Pemrograman PHP dan MySQLuntuk Pemula. Yogyakarta: Andi, 2016.

[9] N. Wahyu, "Pengujian Black Box Testing Pada Aplikasi Action \& Strategy Berbasis Android Dengan Teknologi Phonegap," Informatika, 2018.

[10] Aprilian, "Implementasi 11 Faktor Software Quality - Mc Call's," 2013. https: //themostwowpartner.wordpress.com/tag/kebutuhan-fungsional/.

[11] S. Budiyono, Manajemen Penelitian Pengembangan (Research \& Development). Yogyakarta: Aswaja Pressindo, 2016.

[12] dkk Sariani, "Pengembangan Modul Pembelajaran Geografi Berbasis Peduli Ligkungan Untuk Meningkatkan Sikap Peduli Lingkungan Siswa Pada Materi Sumber Daya Alam Di Kelas Xi Ips Sma Bina Utama Pontianak," J. GeoEco, vol. 3, 2017, [Online]. Available: https: //jurnal.uns.ac.id/GeoEco/article/download/8996/7994. 